\title{
EFEITOS DA ENTRADA DA IKEA NUM CLUSTER DE PRODUÇÃO DE MÓVEIS
}

\author{
V. Eiriz $^{1 *}$; D. Carvalho ${ }^{1}$ \\ 1 Universidade do Minho - Escola de Economia e Gestão, Gualtar 4710-057 Braga, Portugal \\ *veiriz@eeg.uminho.pt
}

Artigo submetido em 03/04/2016 e aceito em 24/04/2016

\begin{abstract}
RESUMO
A entrada de uma empresa multinacional num cluster, entendido como aglomeração geográfica num determinado local ou região, geralmente de pequenas e médias empresas especializadas num sector e sectores relacionados, produz efeitos sobre as empresas que constituem o cluster. No sentido de compreender os principais efeitos da entrada de uma multinacional na estratégia das empresas instaladas num cluster, foi analisada a entrada da empresa sueca IKEA no cluster de produção de móveis de Paços de Ferreira e Paredes, em Portugal. A técnica de recolha de dados utilizada para obtenção de dados primários foi o inquérito por questionário. $\mathrm{Na}$ amostra predominam pequenas empresas, o que corresponde à estrutura de empresas
\end{abstract}

dominante no cluster estudado. Em termos de resultados, mais de metade da amostra considera não ter havido impacto com a entrada da multinacional. No entanto, as empresas que reconhecem ter havido elevado impacto, consideram que o mesmo foi negativo. Os fatores de competitividade que melhoraram de forma mais significativa após a entrada da IKEA foram o desenvolvimento de novos produtos e as estratégias de exportação. As principais respostas das empresas instaladas à entrada da multinacional foram a internacionalização do negócio e o desenvolvimento de estratégias genéricas de diferenciação e focalização baseada na diferenciação.

PALAVRAS-CHAVE: multinacional, cluster, móveis, estratégia, vantagem competitiva.

\section{EFFECTS OK IKEA'S ENTRY INTO A FURNITURE PRODUCTION CLUSTER}

The entry of a multinational into a cluster, a geographic agglomeration in a given place or region of predominantly small and medium enterprises specialized in a given industry or related industries, impacts the incumbent in the cluster. Aiming to identify the main effects of a multinational entry on the firms' strategy in a cluster, it was analyzed the entry of IKEA, a Swedish multinational, into the cluster of furniture production in Paços de Ferreira and Paredes, in Portugal. In this study, the data collection technique to access primary data was a survey. The sample has small enterprises, which is similar to the structure of firms in the studied cluster.
Results show that more than half the sample thinks that the entry of the multinational had not affected them. However, the firms that acknowledge a significant impact, assess that impact as negative. The competitiveness factors that have improved more significantly after IKEA's entry were new product development and exporting strategies. The main responses of incumbent firms to the multinational entry were internationalization and the development of generic strategies of differentiation and focus based on differentiation.

KEYWORDS: multinational, cluster, furniture, strategy, competitive advantage 


\section{INTRODUÇÃO}

O objetivo deste artigo é compreender o efeito que a entrada duma multinacional num cluster provoca nas empresas instaladas nesse cluster. Existem muitos estudos sobre o efeito da entrada de multinacionais na economia dos países onde entram. Contudo, o efeito dessa entrada em clusters, e mais especificamente sobre o comportamento estratégico das empresas existentes nesse cluster, normalmente pequenas e médias empresas, é menos conhecido.

Numa era de globalização cada vez mais acentuada, as empresas podem procurar capital, bens, informação e tecnologia em qualquer parte do mundo. Poderá pensar-se que com a abertura dos mercados e a melhoria dos transportes e comunicações, a localização duma empresa perdeu alguma da sua importância (Porter, 1998). No entanto, a localização das empresas continua a ser um aspeto importante como o prova, por exemplo, o facto de nos últimos anos se verificar um interesse crescente pelo estudo dos clusters (e.g., Bell et al., 2005; Engelstoft et al., 2006; Hervas-Oliver et al., 2015).

Os clusters podem ser entendidos como aglomerações de empresas, geralmente de pequenas e médias empresas especializadas num sector e sectores relacionados e instaladas num determinado local ou região no qual interagem entre si. De acordo com Porter (1998), os clusters afetam a competitividade através do aumento da produtividade das empresas inseridas na região, através da sua contribuição positiva para a inovação, e estímulo para a criação de novos negócios que se difundem e reforçam o próprio cluster onde se inserem. As empresas instaladas num cluster têm uma maior probabilidade de alcançar vantagens competitivas, quer ao nível de eficácia operacional, quer ao nível estratégico.

De uma forma geral, no que respeita aos contributos das empresas multinacionais para os clusters, Enright (2000) sugeriu que o impacto das empresas multinacionais numa economia está relacionado com o carácter e forma dos bens da empresa investidora, com os recursos do local, com as capacidades da economia que acolhe a empresa multinacional, e com as ferramentas organizacionais através das quais a multinacional e os agentes locais interagem. Os principais contributos que uma empresa multinacional pode dar a uma economia incluem a criação de emprego, formação, transferência de tecnologia, criação de capital, contribuição para a balança de pagamentos através do fomento do comércio internacional, criação de expectativas de procura, estímulo do empreendedorismo e efeitos sobre fornecedores, clientes e concorrentes (Enright, 2000; Dunning, 1993; Hallin and Lind, 2012).

$\mathrm{Na}$ perspetiva das empresas locais, o investimento das empresas multinacionais poderá beneficiá-las na medida em que as empresas locais podem observar as tecnologias, práticas e estratégias das multinacionais, tendo também a oportunidade de reproduzir estas técnicas nas suas próprias operações (Barbosa e Eiriz, 2009a; Barbosa e Eiriz, 2009b; Blomström e Kokko, 1998). São disso exemplo a adoção de novas tecnologias de produção, estratégias de marketing, métodos de controlo de inventário e procedimentos para a motivação dos funcionários. No pressuposto que as empresas multinacionais produzam efeitos positivos nos locais onde se instalam, a concorrência com empresas locais pode efetivamente melhorar a produtividade destas últimas.

Num estudo sobre o impacto das operações das empresas multinacionais em clusters, Nachuma e Keeble (2003) assinalaram que as filiais estrangeiras das multinacionais obtêm bens e recursos específicos internamente na própria multinacional, e tendem, por via disso, a isolar-se do cluster e a distinguir-se de forma considerável das empresas que o compõe. Por outro lado, no sentido contrário, há filiais estrangeiras que interagem intensivamente com as outras empresas do cluster e desenvolvem ligações locais semelhantes aos das empresas nacionais. Quando uma empresa integra um cluster, pretende ter acesso a determinados bens que são mais fácil e 
eficientemente fornecidos de forma externa do que de forma interna, sendo que o acesso a esses bens se torna mais eficaz devido à proximidade geográfica. A natureza e a dimensão do cluster são afetadas por fatores como as ligações da multinacional no mercado de trabalho local; o relacionamento com os fornecedores; a interação com clientes; networking, colaboração e concorrência com empresas e outras organizações locais para além de clientes e fornecedores; e aprendizagem e criatividade coletivas (Nachuma e Keeble, 2003).

Por outro lado, a entrada de multinacionais pode afetar negativamente as empresas locais, na medida em que as primeiras conquistam os melhores fornecedores e distribuidores de bens e serviços quer através da utilização da sua capacidade máxima, quer através de acordos de não concorrência. Neste sentido, as empresas locais podem ser forçadas a mudar para fornecedores e distribuidores inferiores, comprometendo a sua vantagem estratégica e dando assim lugar a um efeito de queda de desempenho e saída (Spencer, 2008). Este efeito ocorre quando as multinacionais afetam a concorrência nos produtos locais, mão-de-obra, ou mercados financeiros. A entrada de multinacionais pode ainda limitar o acesso das empresas locais a recursos escassos, elevando os preços de bens essenciais, inclusivamente os mais básicos como energia e água.

Existem quatro opções estratégicas das empresas de um cluster perante a entrada de uma empresa multinacional (Jaffe et al., 2005): atacar a multinacional que entra no cluster; cooperar com a multinacional; defender a sua posição inicial; ou sair do mercado. Estas estratégias a adotar pelas empresas instaladas no cluster estão relacionadas com a pressão para a globalização numa indústria.

Quando as empresas do cluster carecem de vantagens específicas e operam em indústrias altamente localizadas devem assumir uma estratégia defensiva, ou seja, as empresas domésticas devem adquirir as competências necessárias para se defenderem da multinacional. A alternativa a esta opção é sair do mercado. Pelo contrário, quando as vantagens específicas das empresas locais são elevadas, uma possível estratégia passa por atacar a empresa multinacional, concorrendo com ela no seu mercado.

Quando a pressão para a globalização da indústria é forte e as empresas do cluster têm vantagens específicas acentuadas, a estratégia passa por atacar. Por exemplo, a melhor opção pode envolver uma estratégia que aposte claramente na exportação, procurando aumentar quotas de mercado com base na diferenciação do produto ou na liderança em custos. No mesmo contexto de forte globalização mas caracterizado pela existência de vantagens específicas reduzidas por parte das empresas locais, a melhor opção para estas é cooperar com a multinacional. Neste caso, uma das estratégias recomendadas é a formação de alianças que permitam o acesso a recursos das empresas multinacionais (Jaffe et al., 2005; Poulis et al., 2012).

A formação de alianças estratégicas proporciona uma das melhores oportunidades para a transferência de conhecimento entre a empresa multinacional e as empresas locais. Esta mobilidade de recursos baseada na interação entre empresas proporciona a difusão de conhecimento pelas empresa locais. Isto é, as vantagens que se retiram em termos da assimilação do conhecimento não são apenas para as empresas que participam na aliança, mas também para as restantes empresas do cluster por via da interação com a multinacional e com as suas parceiras (Spencer, 2008).

A estratégia competitiva pode assumir ações ofensivas ou defensivas com o objetivo de criar uma posição na indústria. Porter (1985) identificou três estratégias genéricas, as quais podem ser utilizadas individualmente ou em conjunto: liderança em custos, diferenciação e focalização. As três estratégias genéricas envolvem diferentes caminhos para alcançar a vantagem competitiva. Enquanto as estratégias de liderança em custos e de diferenciação procuram a vantagem competitiva num mercado-alvo amplo, as estratégias de focalização visam a vantagem em custo (focalização baseada em custos) ou na diferenciação (focalização baseada na diferenciação) num mercado-alvo 
restrito. As ações específicas necessárias para a implementação de cada uma das três estratégias dependem de cada indústria e também das estratégias genéricas que são possíveis de adotar por cada empresa.

O resto do artigo está organizado da seguinte forma. Na secção seguinte descreve-se o contexto e metodologia adoptada na pesquisa, incluindo os procedimentos de recolha e tratamento de dados. Na secção 3 são apresentados e discutidos os resultados. Finalmente, na secção 4, o artigo conclui com a apresentação dos seus principais contributos, limitações e sugestões de pesquisa futura.

\section{MATERIAIS E MÉTODOS}

Este estudo empírico foi realizado no maior cluster de produção de móveis existente em Portugal. Este cluster localiza-se nos concelhos de Paços de Ferreira e Paredes, no norte do país. Para além deste cluster ser reconhecidamente aceite como a principal aglomeração de empresas do sector em Portugal, ele foi também escolhido em virtude da maior empresa de móveis do mundo, a sueca IKEA, se ter aí instalado com a abertura de três fábricas de grande dimensão, confirmando desta forma a relevância do cluster na indústria de produção de móveis.

A empresa sueca IKEA, fundada em 1943, é o maior distribuidor de móveis do mundo. No ano fiscal terminado em 31 de agosto de 2015, de acordo com uma síntese do seu relatório anual (IKEA, 2015), a empresa teve um volume de vendas global de 32,7 mil milhões de Euros (assumindo uma cotação de quatro Reais por Euro, corresponde a 130,8 mil milhões de Reais). Possuía 328 lojas distribuídas por 28 países, e 43 fábricas em 11 países. Apesar de ter uma presença global, 67 por cento do seu volume de vendas é realizado na Europa. O essencial da sua oferta é constituída por móveis, artigos de decoração, e utilidades para o lar caracterizados por um desenho simples de inspiração nórdica, grande funcionalidade dos produtos, e baixos preços. Os seus baixos preços resultam da simplicidade dos seus produtos e serviços, e economias de escala nas compras e produção. O seu número total de colaboradores era no final do exercício fiscal de 2015 de 155000 , dos quais 116500 na distribuição, 20500 na produção, e 18000 nas compras e outros serviços.

A empresa entrou em Portugal com a abertura da sua primeira loja em 2004. Em 2016 abriu a sua quarta loja no país, onde mantém planos de expansão. Em 2007 abriu a sua primeira de três fábricas que possui no cluster em estudo. A empresa não divulga dados por país mas a nossa pesquisa documental com base em dados da Associação Empresarial de Portugal (AEP, 2016) mostra que, no total, estas fábricas empregavam 1348 colaboradores e tiveram um volume de negócios de 146 milhões de Euros em 2015 (aproximadamente 584 milhões de Reais), valores que naturalmente não incluem a operação varejista.

Para se ficar com uma ideia da importância destas fábricas na produção de móveis em Portugal, a nossa análise do ranking dos dez maiores produtores da indústria mostra que a IKEA era em 2015 o produtor de maior dimensão em Portugal com mais do triplo das vendas do segundo operador (no total das vendas dos dez maiores fabricantes de móveis em Portugal, a IKEA possuía uma quota de 41,7 por cento dessas vendas; 71,5 por cento se calcularmos a relação entre o total da IKEA e o total das restantes nove empresas). Assinale-se que este volume de vendas diz respeito exclusivamente à produção de móveis pois as vendas do varejo são contabilizadas noutra sociedade comercial. Naturalmente, as fábricas produzem móveis para fornecer em exclusivo as próprias lojas da IKEA. O destino destas vendas por mercado ou por loja não é divulgado mas, dada a sua dimensão, esta produção destina-se a vários países, predominantemente europeus.

O objetivo deste estudo foi compreender o efeito da entrada da IKEA no cluster de móveis de Paços de Ferreira e Paredes, em Portugal. A população desta investigação é desta forma constituída pelas empresas que pertencem a esse cluster. Tanto o cluster em estudo como a 
multinacional em causa são, pelas características que acabamos de analisar, particularmente adequados para o tópico desta pesquisa - a compreensão do efeito da entrada duma multinacional num cluster sobre a estratégia das empresas instaladas nesse cluster.

$\mathrm{Na}$ recolha de dados primários foi utilizada a técnica de inquérito por questionário. $\mathrm{O}$ questionário foi desenvolvido tendo em consideração a revisão de literatura apresentada na secção anterior. Questionou-se as empresas sobre alterações nos seus indicadores de desempenho após a entrada da IKEA no cluster com a abertura de fábricas bem assim como sobre as opções estratégicas por elas escolhidas para responder a essa entrada. No desenho do questionário, pretendeu-se compreender o período anterior e posterior à entrada da IKEA. Assim, as questões pretenderam aferir as alterações ocorridas após a entrada da multinacional no cluster abrangendo o período posterior ao ano 2007.

Quando analisadas as vendas das empresas do cluster em termos internacionais, optou-se por analisar os anos 2008, 2010 e 2013, pois desta forma é possível identificar as alterações ocorridas no ano imediatamente a seguir à entrada da multinacional, sendo que cinco anos foi considerado um período de tempo suficiente para equacionar impactos de mais longo prazo. $\mathrm{O}$ período 2005-2013 foi selecionado para estudar a evolução das empresas relativamente aos seus indicadores de desempenho.

A base de dados das empresas do cluster, incluindo os seus contatos para efeitos de recolha de dados, foi construída através de várias fontes de informação. Em particular, usámos uma base de dados obtida junto da Informa D\&B, uma importante empresa de dados empresariais de Portugal, e explorámos de forma sistemática vários diretórios de empresas online. A nossa população foi constituída por 400 empresas para as quais obtivemos endereço de correio eletrônico, ferramenta essencial de contato na medida em que, por uma questão de custos, aplicámos o questionário online usando a plataforma Qualtrics (www.qualtrics.com).

De entre os 400 contatos efetuados, 50 mensagens foram devolvidas por terem o endereço incorreto e/ou por estarem desatualizados. De entre as 350 empresas efetivamente contatadas, apuraram-se 66 respostas válidas para tratamento de dados. Não obstante todos os cuidados havidos nos procedimentos de recolha de dados, incluindo a repetição de pedidos de resposta e contatos telefónicos, e do número total de resposta ter ficado algo aquém do que seria desejável, a taxa de resposta (18,9 por cento das empresas contatadas responderam ao questionário) foi deveras elevada e acima do que é habitual neste tipo de estudos.

$\mathrm{Na}$ análise dos dados recolhidos, procedeu-se à utilização de técnicas estatísticas descritivas utilizado o software de tratamento estatístico IBM SPSS. De entre os 66 respondentes, 56 (84,8 por cento) são gerentes, administradores ou diretores da empresa. A grande maioria (64 |96,9 por cento) trabalha no sector há pelo menos três anos. Em conjunto, estes dois indicadores mostram que os respondentes foram indivíduos experientes, conhecedores da realidade e com posições de relevo nas empresas estudadas, garantindo-nos, desta forma, respostas informadas e conhecedoras da realidade.

Em média, as empresas respondentes possuíam 29,6 colaboradores, sendo que a maior empresa possuía 240 colaboradores. Ou seja, a amostra é constituída por pequenas e médias empresas, correspondente ao tipo de empresas predominante no cluster estudado. A sua idade média (23,3 anos) mostra também que estamos perante empresas que não são jovens mas, em média, possuem uma antiguidade que lhes confere bastante experiência embora, como vimos, mantenham uma dimensão reduzida. De entre as empresas inquiridas, 21,2 por cento atua em exclusivo no mercado externo, enquanto 10,6 por cento atua em exclusivo no mercado doméstico. 
O número de empresas que atua em simultâneo nos dois mercados é de 68,2 por cento. Em síntese, 89,4 por cento das empresas mostra alguma experiência internacional.

\section{RESULTADOS E DISCUSSÃO}

\subsection{O cluster em estudo e a entrada da IKEA}

Tendo em conta a importância dos fatores de localização, questionou-se se as empresas sempre estiveram localizadas no cluster em estudo. Verificou-se que a totalidade das empresas da amostra sempre esteve localizada neste cluster. Isto significa que aquando da sua constituição, as empresas de fabricação de móveis estudadas optaram de imediato por se instalar no cluster. Foi ainda pedido às empresas para classificarem quanto à relevância os fatores de escolha da sua localização (Tabela 1). O principal objetivo desta questão foi perceber qual a influência do cluster na estratégia da empresa.

Tabela 1 - Fatores para localizar a empresa no cluster

\begin{tabular}{|c|c|c|c|c|c|c|c|c|c|}
\hline \multirow{2}{*}{ Fatores de localização } & \multirow[b]{2}{*}{1} & \multirow[b]{2}{*}{2} & \multirow[b]{2}{*}{3} & \multirow[b]{2}{*}{4} & \multirow[b]{2}{*}{5} & \multicolumn{2}{|c|}{ Total } & \multirow{2}{*}{ Média } & \multirow{2}{*}{$\begin{array}{l}\text { Desvio- } \\
\text { padrão }\end{array}$} \\
\hline & & & & & & $\mathbf{N}$ & $\%$ & & \\
\hline Acesso a recursos e tecnologias especializadas & $5,6 \%$ & $18,5 \%$ & $25,9 \%$ & $44,4 \%$ & $5,6 \%$ & 54 & $100 \%$ & 3,3 & 1,0 \\
\hline Aumento da produtividade & $5,6 \%$ & $11,1 \%$ & $35,2 \%$ & $44,4 \%$ & $3,7 \%$ & 54 & $100 \%$ & 3,3 & 0,9 \\
\hline Partilha de informação e inovação & $5,6 \%$ & $20,4 \%$ & $35,2 \%$ & $37,0 \%$ & $1,8 \%$ & 54 & $100 \%$ & 3,1 & 0,9 \\
\hline Facilidades num processo de internacionalização & $9,3 \%$ & $20,4 \%$ & $35,2 \%$ & $27,8 \%$ & $7,4 \%$ & 54 & $100 \%$ & 3,0 & 1,1 \\
\hline Criação de novas oportunidades de negócio & $18,5 \%$ & $22,2 \%$ & $27,8 \%$ & $27,8 \%$ & $3,7 \%$ & 54 & $100 \%$ & 2,8 & 1,2 \\
\hline Acesso a novas estratégias de Marketing & $9,3 \%$ & $27,8 \%$ & $44,4 \%$ & $16,7 \%$ & $1,8 \%$ & 54 & $100 \%$ & 2,7 & 0,9 \\
\hline Outro & $47,6 \%$ & $4,9 \%$ & $19,0 \%$ & $9,5 \%$ & $19,0 \%$ & 21 & $100 \%$ & 2,5 & 1,6 \\
\hline
\end{tabular}

Legenda: 1 - Não é relevante; 2 - Pouco relevante; 3 - Nem pouco nem muito relevante; 4 - Relevante; 5 - Muito relevante.

Fonte: Elaborado pelos autores

O "acesso a recursos e tecnologias especializadas" é o aspeto mais relevante que levou as empresas a instalarem-se no cluster, com 50 por cento das empresas a considerar que é relevante ou muito relevante. Logo de seguida, são referidos o "aumento da produtividade" e a "partilha de informação e inovação". Por outro lado, importa referir que a "criação de novas oportunidades de negócio" foi o aspeto que mais dividiu as empresas quanto à sua relevância, algo que é ilustrado por um valor médio de 2,8. Estes resultados sugerem que o cluster detém uma influência significativa na estratégia das empresas, uma vez que as vantagens de pertencer ao cluster são positivamente percecionadas pelas empresas que optaram por se instalar nele.

O questionário procurou aferir as alterações havidas em indicadores importantes das empresas que tenham resultado da entrada da IKEA, tendo sido colocada uma questão com esse propósito. Em particular, questionou-se a evolução do peso das vendas das empresas a nível internacional antes e após a entrada da IKEA no cluster (Gráfico 1). 


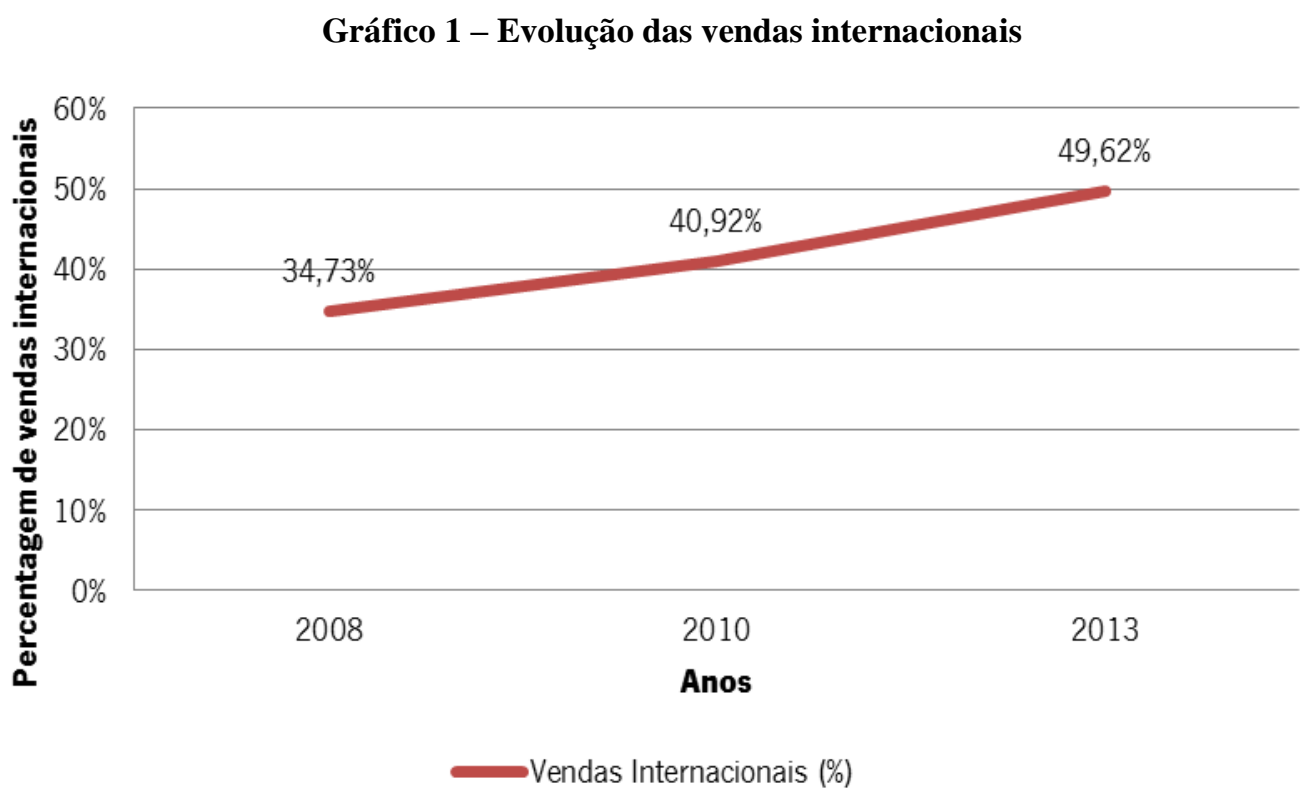

Fonte: Elaborado pelos autores

Tendo em conta a percentagem de volume de negócios a nível internacional para os anos 2008, 2010 e 2013, verificou-se um aumento dessa percentagem que passou de 34,7 por cento em 2008 para 49,6 por cento em 2013. A escolha destes anos deveu-se ao facto de serem posteriores à entrada da IKEA no cluster que, como vimos anteriormente, ocorreu em 2007 com a abertura da primeira unidade de produção. Desta forma, foi possível verificar o comportamento das empresas após a entrada da multinacional, tendo-se observado um aumento do peso das vendas a nível internacional entre 2008 e 2013 na ordem dos 14,9 pontos percentuais. Desta forma, a evolução positiva do peso das exportações das empresas sugere que a entrada da IKEA poderá ter contribuído para o aumento do peso relativo das exportações, tal como é sugerido pela literatura revista no início do artigo. Naturalmente, não é de excluir que haja outras causas que tenham contribuído para o aumento do grau de internacionalização apurado como poderá ser o caso de alguma retração do mercado doméstico havida no período em estudo. Em todo o caso, é inegável que os investimentos da IKEA no cluster trouxeram uma maior visibilidade para o cluster que poderá ter favorecido as vendas internacionais das empresas estudadas.

Afim de compreender o desempenho das empresas antes e depois da entrada da IKEA, as empresas foram questionadas sobre a evolução desses indicadores entre 2005 e 2013 (Tabela 2). Foram utilizados diferentes indicadores tendo sido usada uma escala Likert com cinco níveis para cada um dos indicadores, entre 1 que significa "Diminuiu muito (diminuiu mais de $20 \%$ )" e 5 que significa "Aumentou muito (aumentou mais de 20\%)". Ou seja, a análise foi baseada em medidas subjetivas tendo em consideração as percepção dos respondentes sobre a evolução dos indicadores no período em análise.

Verifica-se que as empresas inquiridas apresentaram uma tendência de evolução positiva (superior a 3) em todos os indicadores apresentados na Tabela 2. Os indicadores em que essa evolução foi mais significativa (embora com valores médios inferiores a 4) foram: "Melhorias nas competências da sua empresa", "Volume de exportação", "Nível de inovação", "satisfação dos clientes" e "Qualidade do produto". 
Tabela 2 - Evolução dos indicadores de desempenho das empresas entre 2005 e 2013

\begin{tabular}{|c|c|c|c|c|c|}
\hline Indicadores de desempenho & $\mathbf{N}$ & Média & $\begin{array}{l}\text { Desvio- } \\
\text { padrão }\end{array}$ & Mínimo & Máximo \\
\hline Melhorias nas competências da sua empresa & 55 & 3,87 & 0,80 & 1 & 5 \\
\hline Volume de exportação & 55 & 3,84 & 1,00 & 1 & 5 \\
\hline Nível de inovação & 55 & 3,82 & 0,72 & 1 & 5 \\
\hline Satisfação dos clientes & 55 & 3,76 & 0,74 & 1 & 5 \\
\hline Qualidade do produto & 55 & 3,75 & 0,80 & 1 & 5 \\
\hline Volume de negócios & 55 & 3,55 & 1,26 & 1 & 5 \\
\hline Taxa de crescimento das vendas & 55 & 3,53 & 1,18 & 1 & 5 \\
\hline Nível da produtividade & 54 & 3,52 & 1,06 & 1 & 5 \\
\hline Quota de mercado & 55 & 3,49 & 1,03 & 1 & 5 \\
\hline Rentabilidade & 54 & 3,37 & 1,03 & 1 & 5 \\
\hline Motivação do pessoal & 55 & 3,36 & 0,87 & 1 & 5 \\
\hline Salários & 55 & 3,35 & 0,75 & 1 & 5 \\
\hline Número de trabalhadores & 55 & 3,25 & 1,22 & 1 & 5 \\
\hline Outro & 5 & 1,60 & 1,34 & 1 & 4 \\
\hline
\end{tabular}

Legenda: 1 - Diminuiu muito (diminuiu mais de 20\%); 2 - Diminuiu; 3 - Manteve-se; 4 - Aumentou; 5 - Aumentou muito (aumentou mais de 20\%)

Fonte: Elaborado pelos autores.

Estes resultados mostram que as empresas de um cluster quando confrontadas com a entrada de uma multinacional, alteram o seu comportamento, incentivado pela introdução de inovação por parte da multinacional. Esta resposta é dada geralmente através do recurso à imitação e do desenvolvimento de competências (Hallin and Lind, 2012). Desta forma, os resultados obtidos com a evolução dos indicadores de desempenho das empresas estudadas vão de encontro ao advogado pela literatura.

Importa ainda referir que o indicador que mais se próxima do valor 3 (isto é, manteve-se) são os "Salários". Ou seja, no período entre 2005 e 2013 é de crer que a IKEA não provocou um efeito de subida dos salários no cluster. Embora este fenómeno pudesse ocorrer, é importante notar que a própria IKEA baseia a sua estratégia em custos baixos motivo pelo qual não é de estranhar que ela não tenha provocado um efeito de subida nos custos da mão-de-obra. É aliás de admitir que os salários locais, comparativamente baixos em relação a muitos países europeus, tenha sido um dos fatores de localização da IKEA no cluster.

De uma forma geral, com os resultados apresentados nesta secção conclui-se que as empresas consideram não ter havido alterações significativas nos seus indicadores de desempenho como resultado da entrada da IKEA no cluster em que elas estão instaladas, embora assinalem melhorias em vários indicadores de desempenho.

\subsection{Efeitos na estratégia empresarial}

No que se refere à percepção das empresas relativamente ao impacto da entrada da IKEA no seio do cluster, foi-lhes pedido para classificar, numa escala de 1 a 5, o impacto que a IKEA teve na empresa. A Tabela 3 apresenta os principais resultados, considerando ainda se o impacto é positivo ou negativo. 
Tabela 3 - Grau de impacto nas empresas com entrada da IKEA

\begin{tabular}{|c|c|c|c|c|}
\hline \multirow{2}{*}{ Grau de impacto } & \multicolumn{2}{|c|}{ Impacto } & N & Total \\
\cline { 2 - 5 } & Positivo & Negativo & 21 & $45,6 \%$ \\
\hline 1 & $30,4 \%$ & $15,2 \%$ & 11 & $23,9 \%$ \\
\hline 2 & $17,4 \%$ & $6,5 \%$ & 8 & $17,4 \%$ \\
\hline 3 & $6,5 \%$ & $10,9 \%$ & 4 & $8,7 \%$ \\
\hline 4 & $0,0 \%$ & $8,7 \%$ & 2 & $4,3 \%$ \\
\hline 5 & $0,0 \%$ & $4,3 \%$ & 46 & $100,0 \%$ \\
\hline Total & $54,3 \%$ & $45,7 \%$ & & \\
\hline
\end{tabular}

Legenda: 1 - Nenhum impacto; 5 - Muito impacto.

Fonte: Elaborado pelos autores.

Os resultados mostram que 45,6 por cento dos inquiridos considera que a entrada da IKEA no seio do cluster não teve qualquer impacto na sua empresa. Destacam-se ainda os 23,9 por cento que julgam ter havido pouco impacto. Por outro lado, 4,3 por cento das empresas notaram muito impacto com a entrada da multinacional, tendo este sido avaliado como negativo. De uma forma geral, verificou-se assim que a maioria das empresas não reconhece ter havido impacto ou notaram pouco impacto com a entrada da IKEA, embora um pequeno número de empresas reconheça um grande impacto negativo.

No sentido de melhor percebermos os efeitos da entrada da IKEA, para além da questão anterior foi perguntado às empresas se denotaram melhorias nas variáveis constantes da Tabela 4 como resultado da entrada da IKEA. Ou seja, para além duma questão genérica do impacto (Tabela 3) procuramos identificar de forma mais específica alguns fatores de competitividade que tenham sofrido alteração como resultado da entrada da IKEA. Aos inquiridos foi questionado o seu grau de concordância com cada um dos fatores com base numa escala de Likert.

Tabela 2 - Grau de concordância relativo à melhoria dos fatores de competitividade com a entrada da IKEA

\begin{tabular}{|l|c|c|c|c|c|}
\hline Fatores de competitividade & $\mathbf{N}$ & Média & $\begin{array}{c}\text { Desvio- } \\
\text { padrão }\end{array}$ & Mínimo & Máximo \\
\hline Desenvolvimento de novos produtos & 56 & 2,64 & 1,14 & 1 & 5 \\
\hline Estratégias de exportação & 56 & 2,58 & 1,13 & 1 & 5 \\
\hline Controlo de qualidade & 56 & 2,53 & 0,98 & 1 & 4 \\
\hline Formação de recursos humanos & 56 & 2,49 & 0,96 & 1 & 4 \\
\hline Estratégias de marketing & 56 & 2,42 & 0,99 & 1 & 5 \\
\hline Métodos de controlo de inventário & 56 & 2,36 & 0,91 & 1 & 4 \\
\hline Padronização dos canais de fornecimento e distribuição & 56 & 2,36 & 0,95 & 1 & 4 \\
\hline Serviços subcontratados/ encomendas & 56 & 2,35 & 0,97 & 1 & 4 \\
\hline Novas tecnologias de produção & 56 & 2,33 & 0,92 & 1 & 4 \\
\hline
\end{tabular}

Legenda: 1 - Discordo totalmente; 2 - Discordo; 3 - Nem concordo nem discordo; 4 - Concordo; 5 - Concordo totalmente.

Fonte: Elaborado pelos autores

Os fatores com maior média são o "desenvolvimento de novos produtos", seguido das "estratégias de exportação". Os "serviços subcontratados/ encomendas" e as "novas tecnologias de produção" foram os fatores considerados pelos respondentes com menor média. No entanto, importa referir que todas estas variáveis apresentam médias entre 2 (Discordo) e 3 (Nem concordo nem discordo), mostrando que as empresas estudadas não reconhecem melhorias nestas variáveis como consequência da entrada da IKEA no seu cluster. Ou seja, as empresas não reconhecem que a IKEA lhes tenha provocado melhorias dos fatores de competitividade algo que poderá ser explicado em parte porque naturalmente essas melhorias são difíceis de se verificarem ou observarem de forma direta. 
Neste estudo, quisemos ainda perceber quais foram as opções estratégicas adotadas pelas empresas do cluster na sequência da entrada da IKEA. Foi pedido aos respondentes para assinalar, de entre as opções constantes da Tabela 5, quais foram as suas respostas à entrada da IKEA (as 56 empresas que responderam a esta questão podiam responder a mais do que uma opção).

Tabela 5 - Resposta das empresas à entrada da IKEA

\begin{tabular}{|c|c|c|}
\hline Opções de resposta & $\mathbf{N}$ & $\%$ \\
\hline Internacionalizar o negócio & 18 & $32,10 \%$ \\
\hline Outra & 15 & $26,80 \%$ \\
\hline Obter uma quota de mercado significativa com base na diferenciação do produto & 14 & $25,00 \%$ \\
\hline Adotar uma estratégia de focalização baseada na diferenciação & 13 & $23,20 \%$ \\
\hline Defender a sua posição inicial & 10 & $17,90 \%$ \\
\hline Adquirir competências para obter vantagens & 5 & $8,90 \%$ \\
\hline Adotar uma estratégia de focalização baseada nos custos (um segmento da indústria) & 2 & $3,60 \%$ \\
\hline Atacar a multinacional (competir com a IKEA no seu mercado) & 1 & $1,80 \%$ \\
\hline Cooperar com a multinacional (formação de alianças) & 1 & $1,80 \%$ \\
\hline $\begin{array}{l}\text { Obter uma quota de mercado significativa com base na liderança em custos (vários } \\
\text { segmentos da indústria) }\end{array}$ & 1 & $1,80 \%$ \\
\hline
\end{tabular}

Fonte: Elaborado pelos autores.

De realçar que 32,1 por cento das empresas internacionalizaram o seu negócio como estratégia de resposta à entrada da IKEA, resultado que é consistente com o apresentado no Gráfico 1. A segunda estratégia mais usada foi "obter uma quota de mercado significativa com base na diferenciação do produto", adotada por 25 por cento das empresas, seguida de "adotar uma estratégia de focalização baseada na diferenciação" com 23,2 por cento das empresas. Na Tabela 5 é ainda possível verificar que as estratégias menos usadas pelas empresas foram "atacar a multinacional (competir com a IKEA no seu mercado)", "cooperar com a multinacional (formação de alianças)" e "obter uma quota de mercado significativa com base na liderança de custos (vários segmentos da indústria)". Importa ainda destacar os 26,8 por cento das empresas que adotaram estratégias não incluídas nas opções dadas, destacando-se claramente as respostas que indicam que dado a IKEA se encontrar num segmento de mercado diferente, não adotaram qualquer estratégia em reação à entrada da IKEA.

Quisemos também verificar se as respostas das empresas do cluster à entrada da IKEA poderiam estar associadas à dimensão das empresas. Os resultados mostram que com a entrada da IKEA no cluster, as empresas mais pequenas (menos de 10 trabalhadores) optam sobretudo por defender a sua posição inicial e melhorar a sua quota de mercado com base na diferenciação do produto. No que concerne às empresas que empregam entre 10 a 49 colaboradores, destaca-se o facto de 80,8 por cento das empresas optarem por internacionalizar o negócio. As pequenas empresas responderam também com a obtenção de uma quota de mercado significativa com base na diferenciação do produto e com a adotação de uma estratégia de focalização baseada na diferenciação, com 50,8 por cento e 57,7 por cento, respetivamente.

Finalmente, destaca-se o facto de as médias empresas com 50 a 99 trabalhadores terem optado essencialmente por internacionalizar o negócio (50 por cento), sendo que as empresas com um número de trabalhadores entre 100 e 250, responderam apenas com a aquisição de competências para obter vantagens (30,3 por cento). Em síntese, os resultados não parecem variar em função da dimensão das empresas.

Os resultados apresentados nesta secção sugerem que a pressão para a globalização do negócio é forte e que as empresas do cluster têm vantagens específicas acentuadas. Desta forma, a 
sua estratégia passou por apostar na internacionalização, baseando essa opção sobretudo numa estratégia de diferenciação do produto (Jaffe et al., 2005; Porter, 1985; Poulis et al., 2012).

Se tivermos presente que a IKEA é uma empresa que possui uma oferta global de móveis para todo o mercado e que essa oferta se baseia em preços baixos (embora complementados com fatores valorizado pelo cliente como o desenho, serviço e ofertas complementares sobretudo em termos de decoração e utilidades para o lar), não é de todo surpreendente que as empresas portuguesas do cluster estudado, na impossibilidade de terem o baixo nível de custos da IKEA devido à sua pequena dimensão e impossibilidade de criar economias de escala, apostem na diferenciação dos seus produtos. Esta diferenciação é efetuada, em primeiro lugar, nos materiais de produção empregues, normalmente de maior qualidade que a IKEA. Por outro lado, alguma dessa diferenciação passa por produzir móveis à medida e segundo especificações próprias de cada cliente (produção esta complementada com entrega e montagem personalizada), algo que não é exequível na IKEA.

Importa ainda referir que a diferenciação permite às empresas portuguesas do cluster praticar preços mais elevados mas obriga, por outro lado, as empresas a posicionarem-se em segmentos mais específicos de mercado, não só no mercado doméstico mas também internacionalmente. Ou seja, a focalização baseada na diferenciação é efetivamente a estratégia mais óbvia que é seguida pelas empresas estudadas como forma de reação à IKEA. Ao adoptar esta estratégia, as empresas do cluster evitam o confronto direto com a IKEA e procuram defender posições em segmentos de mercado em que a própria IKEA é menos capaz.

\section{CONCLUSÃO}

Um cluster tem influência na estratégia das empresas nele instaladas. De igual forma, ao entrar num cluster, uma empresa multinacional pode influenciar as empresas instaladas nesse cluster. No estudo realizado sobre o efeito da entrada da IKEA no principal cluster de móveis em Portugal verificou-se que a perceção das empresas locais aponta para o facto de não terem reconhecido alterações significativas nos seus indicadores de desempenho como resultado da entrada da IKEA.

Em particular, mais de metade das empresas inquiridas consideram não ter havido impacto na sua empresa como resultado da entrada da multinacional sueca, líder mundial da produção e distribuição de móveis. No entanto, as poucas empresas que consideraram ter havido elevado impacto, consideram que o mesmo foi negativo.

Ainda assim, as empresas estudadas assinalam mudanças na sua estratégia quando confrontadas com as suas opções antes e depois da entrada da IKEA. Estes resultados sugerem uma aparente contradição pois, se por um lado, a maioria das empresas assinalam não haver impactos da entrada da IKEA no seu cluster, o certo é que, por outro lado, alteram o seu comportamento e opções estratégicas como consequência dessa entrada. Em síntese, é de crer que a IKEA possua um efeito indireto e não imediato no comportamento e estratégia das empresas locais desde logo porque elas percebem a IKEA como uma empresa a atuar num segmento de mercado distinto do seu.

No estudo realizado, as principais respostas das empresas como resultado da entrada da IKEA passaram pela internacionalização do seu negócio e pela obtenção de quotas de mercado significativas em segmentos específicos do mercado com base na diferenciação do produto. Ou seja, as empresas estudadas parecem fugir ao mercado de baixos custos que é claramente dominado pela IKEA e adoptam estratégias de focalização em segmentos de mercado mais específicos que premeiam a diferenciação do produto, normalmente baseado em móveis feitos à medida e com a incorporação de materiais de melhor qualidade do que a IKEA. 
A principal limitação deste estudo tem a ver com a população e amostra. Em primeiro lugar, mesmo tratando-se de um estudo quantitativo, a nossa opção foi a de estudar um único cluster e o efeito da entrada duma multinacional específica nesse mesmo cluster. Esta opção teve, por um lado a vantagem de nos ter permitido analisar o problema em investigação - o efeito da entrada de multinacionais num cluster - duma forma mais concreta através do estudo do caso escolhido. Contudo, esta opção torna os resultados aplicáveis somente ao cluster e à multinacional em estudo, não podendo ser efetuadas generalizações para outros clusters e multinacionais. Em segundo lugar, a pequena dimensão da amostra suscita a dúvida se os resultados obtidos representam verdadeiramente toda a população de empresas instaladas no cluster. Trata-se duma limitação clássica destes estudos, embora a elevada percentagem de respostas obtidas e a caracterização dos indivíduos e empresas respondentes nos façam crer que os resultados apresentados são válidos e fiáveis.

Um segunda limitação de natureza metodológica, também ela natural, foi a utilização do questionário como único método de recolha de dados. Se, por um lado, esta técnica nos permite alcançar um número elevado de indivíduos da população, por outro lado, não permite explorar efeitos específicos que seria possível compreender melhor analisando algumas empresas em particular.

Relativamente a pistas para trabalhos de investigação futura sugerem-se pesquisas que permitam ultrapassar as limitações identificadas. Em particular, é recomendável estudar empresas do cluster com maior profundidade, adoptando técnicas de recolha de dados como por exemplo entrevistas junto dessas empresas que permitam uma maior profundidade e compreensão do impacto da IKEA no seu comportamento e nas suas estratégias. Por outro lado, recomenda-se a replicação deste estudo e estudos semelhantes junto de outros clusters e multinacionais pois é de crer que os impactos da entrada variem com os sectores, territórios e multinacionais em estudo.

A realização de uma investigação científica visa ter utilidade prática para as empresas e seus responsáveis. Este objetivo foi alcançado com a verificação de alterações na estratégia das empresas do cluster estudado, bem como nos indicadores de desempenho das empresas nele instaladas, com a identificação das opções estratégicas escolhidas por essas empresas e, por fim, com a aferição de qual a perceção das empresas do cluster relativamente ao impacto da entrada da multinacional IKEA. Desta forma, esta pesquisa contribuiu para identificar práticas e estratégias ao dispor das empresas quando confrontadas com a entrada de uma multinacional no seio de um cluster em que as empresas estejam instaladas. Este estudo permite ainda aos responsáveis das empresas um melhor conhecimento do tema em estudo, algo que os ajudará a delinear estratégias para desenvolver vantagens competitivas para as suas empresas.

Em termos académicos esta pesquisa deu um contributo válido para compreendermos melhor os efeitos da entrada de uma multinacional num cluster, analisando empiricamente a entrada duma empresa líder do seu sector de atividade e pesquisando os efeitos específicos resultantes junto das empresas instaladas num importante cluster de produção de móveis.

\section{REFERÊNCIAS}

AEP. Estudo de Mercado Sectorial. Associação Empresarial de Portugal. Disponível em : http://www.aeportugal.pt . Acessado em 28 de março de 2016.

BARBOSA, N.; EIRIZ, V. Linking corporate productivity to foreign direct investment: an empirical assessment. International Business Review, v.18, n.1, p.1-13, 2009.

BARBOSA, N.; EIRIZ, V. The role of inward foreign direct investment on domestic entrepreneurship. International Entrepreneurship and Management Journal, v.5, n.3, p.319-339, 2009. 
BELL, S. J.; TRACEY, P.; HEIDE, J. B. The organization of regional clusters. Academy of Management Review, v.34, n.4, p.623-642, 2009.

BLOMSTRÖM, M.; KOKKO, A. Multinational corporations and spillovers. Journal of Economic Surveys, v.12, n.3, p.247-277, 1998.

DUNNING, J. H. Multinational Enterprises and the Global Economy, Addison-Wesley, Workingham, 1993.

ENGELSTOFT, S.; JENSEN-BUTLER, C.; SMITH, I.; WINTHER, L. (2006). Industrial clusters in Denmark: Theory and empirical evidence. Papers in Regional Science, v.85, n.1, p.73-98, 2006.

ENRIGHT, M. Regional clusters and multinational enterprises. International Studies of Management and Organization, v.30, n.2, p.114-138, 2000.

HALLIN, C.; LIND, C. (2012). Revisiting the external impact of MNCs: An empirical study of the mechanisms behind knowledge spillovers from MNC subsidiaries. International Business Review, v.21, n.2, p.167-179, 2012.

HERVAS-OLIVER, J.-L.; GONZALEZ, G.; CAJA, P.; SEMPERE-RIPOLL, F. (2015). Clusters and industrial districts: Where is the literature going? Identifying emerging sub-fields of research. European Planning Studies, v.23, n.9, p.1827-1872, 2015.

IKEA. IKEA Group - Yearly Summary FY, 2015.

JAFFE, E.; NEBENZAHL, I.; SCHORR, I. Strategic options of home country firms faced with MNC entry. Long Range Planning, v.38, n.2, p.183-195, 2005.

NACHUMA, L.; KEEBLE, D. MNE linkages and localised clusters: foreign and indigenous firms in the media cluster of Central London. Journal of International Management, v.9, n.2, p.171-192, 2003.

PORTER, M. E. Competitive advantage: Creating and Sustaining Superior Performance, The Free Press, New York, 1985.

PORTER, M. E. Clusters and new economics of competition. Harvard Business Review, v.76, n.6, p.77-90, 1998.

POULIS, K.; YAMIN, M.; POULIS, E. Domestic firms competing with multinational enterprises: the relevance or resource-accessing alliance formations. International Business Review, v.21, n.4, p.588-601, 2012.

SPENCER, J. (2008). The impact of multinational enterprise strategy on indigenous enterprises: horizontal spillovers and crowding out in developing countries. Academy of Management Review, v.33, n.2, p.341-361, 2008. 